Revista de Ciencias Sociales - Número 69 (2016) - Páginas 121-155

La prostitución en Cuba. Una mirada a sus reguladores jurídico-sociales

\title{
LA PROSTITUCIÓN EN CUBA. UNA MIRADA A SUS REGULADORES JURÍDICO-SOCIALES
}

\author{
PROSTITUTION IN CUBA; A LOOK TO ITS \\ LEGAL AND SOCIAL REGULATORS
}

\author{
ELENA RICARDO OCHOA* \\ Universidad de Holguín (Cuba) \\ ericardo@ict.uho.edu.cu \\ YAMILKA PINO SERA** \\ Universidad de Holguín (Cuba) \\ ypino@ict.uho.edu.cu
}

\section{Resumen}

En el presente artículo las autoras esbozan algunas valoraciones acerca de los múltiples factores sociales y jurídicos que influyen en la prostitución en Cuba. Sitúan la mirada en algunos aspectos de la vida social que regulan el comportamiento de los sujetos, y como reguladores sociales pueden influir en el curso de este fenómeno, ya sea su tendencia a disminuir, acrecentarse, conservar, o modificar, su forma de existencia, en las históricas y actuales circunstancias de la sociedad cubana.

\footnotetext{
* Licenciada en Filosofía e Historia. Profesora del Departamento de Filosofía. Artículo recibido el 4 de mayo de 2016 y aceptado el 15 de julio de 2016.

* Licenciada en Derecho y Master en Ciencias Sociales y Axiología. Profesora del Departamento de Filosofía
}

Revista de Ciencias Sociales - Número 69 (2016) - Universidad de Valparáíso - ISSN 0716-7725-Valparaíso, Chile 


\section{Palabras clave}

Prostitución, factores, reguladores jurídicos y sociales.

\section{Abstract}

In this article the authors outline some valorations about the many social and legal factors that influence the prostitution in Cuba. They focus on some aspects of the social life that regulate the behaviour of these individuals and how the social regulators may influence the course of this phenomenon, wheather it has a tendency to diminsh, to increase, to preserve or to modify its way of existence in the current and historical circumstances of Cuban society.

\section{Keywords}

Prostitution, factors, legal and social regulators.

\section{Introducción}

En las últimas décadas la prostitución ha mostrado una creciente complejización y ha revelado, en un mayor grado, las diversas formas de explotación de la sexualidad ajena que le acompañan; especialmente las relacionadas con la trata de personas para fines sexuales, convertida esta en el tercer negocio más lucrativo de dimensiones transnacionales, después de las armas y las drogas ${ }^{1}$.

Aunque el interés por la prostitución tiene una larga data en el marco de las ciencias sociales y humanísticas que lo privilegian como objeto de estudio, su renovación hunde sus raíces más recientes en los años de la década de 1970; abonado, también, por el ascenso de la lucha por las reivindicaciones de los derechos de los segmentos sociales más oprimidos por razones étnicas, de clase, género, orientación sexual, entre otras; así como por el desarrollo de diversas variantes de teorías feministas y de género.

A lo largo de los últimos años, la actualidad del tema se refleja en la creciente atención que ha ocupado en la agenda de importantes

1. Informe Departamento de Estado, USA, 2001.

Facultad de Derecho y Ciencias Sociales - Universidad de Valparaíso - Chile 
organismos internacionales, gobiernos y ONGs; lo cual se ha traducido en la multiplicación de las normativas legales sobre la prostitución, a partir de los años 90 del pasado siglo. La creciente expansión de los estudios sobre la prostitución ha estado acompañada por múltiples apropiaciones de conceptos, enfoques teóricos y marcos conceptuales; desde los cuales se han realizado significativas aportaciones al conocimiento del fenómeno social; aportaciones que aparecen en una extensa literatura científica.

En el presente artículo sólo será analizado el caso cubano, aunque en algunos puntos aludiremos a estudios realizados en otras sociedades. Al contextualizar estos análisis para el caso de la sociedad cubana, condición indispensable para nuestro estudio, se observa que a partir de finales de los años 80 del siglo pasado, se desarrolla vertiginosamente la prostitución, paralelamente a la multidimensional crisis que sacudió a la sociedad cubana. El reconocimiento oficial, a la altura de finales de los años de la década de 1990, de la amplitud adquirida por la prostitución y sus implicaciones sociales, contribuyeron a que se potenciara como una de las prioridades de trabajo de los grupos de Prevención y Atención Social.

Este fenómeno social se asume como objeto de investigación, especialmente a partir de mediados de la década de 1990, en lo cual se destacan los estudios realizados por la Federación de Mujeres Cubanas, la Policía Nacional Revolucionaria, el Centro de Investigaciones Psicológicas y Sociológicas, Centro de Estudio de la Juventud, Casa de Orientación a la Mujer y la Familia, y la Unión Nacional de Juristas de Cuba.

En el abordaje de la prostitución en la sociedad cubana a partir de dichos años se encuentran los estudios realizados por Elizalde, Rosa M. (1996); Guerrero, Natividad (1996); Díaz, T. y González, G. (1997); Ferrer y Domínguez (1998); Leyva, A. I. (1999); Mustelier, Sandra (2000, 2002); Larralde, Kenia (2005), entre otros, que han dado importantes pasos en el conocimiento de las formas del fenómeno social, su heterogeneidad y los factores socioeconómicos, demográficos y culturales que lo condicionan en las actuales circunstancias. En el presente artículo las autoras esbozan algunas valoraciones acerca de los múltiples factores sociales y jurídicos que influyen en la prostitución en Cuba.

Revista de Ciencias Sociales - Número 69 (2016) - Universidad de Valparaíso - ISSN 0716-7725-Valparáís, Chile 


\section{Elementos teóricos sobre los factores que inciden en la prostitución}

La Organización Mundial de la Salud definió la prostitución como toda "actividad en la que una persona intercambia servicios sexuales a cambio de dinero o cualquier otro bien"2; algunos autores propusieron ampliar la definición con la inclusión de otros rasgos, entre ellos que los actos sexuales son frecuentes y que existe pluralidad de personas (los clientes) con las cuales esos actos se realizan, con predominio de la falta de exclusividad.

Etimológicamente, prostitución proviene del latín prostitutio,ônis, que significa exponer en público, poner en venta. Se trata pues, de relaciones de compraventa de servicios sexuales, irreducible a una relación entre dos.

Es menester recordar que la prostitución es algo más que un acto en el que una persona intercambia sexo por bienes materiales, habida cuenta que la reunión entre los que dan el servicio sexual y sus clientes se produce a través de un determinado proceso de institucionalización grupal. Muestra de lo antes dicho es lo que Chejter ha descrito como formas de intermediación en la prostitución ${ }^{3}$, las cuales son resultado de procesos de institucionalización grupal y, simultáneamente, tienen potencialidad para actuar como estructurantes de los mismos.

En tal sentido, lo que conocemos como diversas variantes de proxenetismo son manifestación de esas formas de intermediación que se revelan en la actuación de individuos y grupos que facilitan los contactos y acuerdos entre las personas que entregan el servicio sexual y sus clientes y les ofrecen determinada protección para que la actividad se ejecute. Otras variantes del proxenetismo son protagonizadas por personas de ambos sexos propietarias de locales destinados al comercio sexual; así como por los individuos dedicados a enseñar la actividad y por traficantes de personas para fines sexuales, entre otros. En el caso

2. Organización Mundial de la Salud, posteriormente OMS, citada por Juan Carlos Romi. La prostitución. Enfoque psiquiátrico, sexológico y médico-legal. Disponible en: http://www.marietan.com/contac.htm [24 de mayo de 2010].

3. CHEJTER, Silvia. Lugar común: la prostitución. Argentina: Eudeba, 2011. 
de esos traficantes, pueden actuar en forma de grupos al interior de la sociedad o responder, a veces simultáneamente, a una extensa organización con ramificaciones internacionales dedicada a la vieja pero renovada y dramática trata de personas para fines sexuales ${ }^{4}$, que en la sociedad cubana actual no son operables. Un aspecto dramático de las relaciones de intermediación por su carácter profundamente deshumanizante, en todas sus variantes, es la presencia en ellas de personas que promueven la entrada de miembros de su familia a la prostitución, las obligan a ejercer esta actividad o las venden a traficantes de personas. Tendríamos que considerar, además, las relaciones que se producen entre las personas en prostitución que, supuestamente, actúan en solitario. Esto último si bien es cierto desde el punto de vista de la no presencia del proxeneta, los desafíos que se presentan a la realización de su actividad, en competencia o conflicto con otros individuos y grupos, puede conducir a la constitución de grupos de apoyo y de coordinación de acciones entre las personas en prostitución.

El conjunto de códigos, acuerdos y costumbres producidos y reproducidos en los marcos de la prostitución son acatados muchas veces por la utilidad que representan; pero otras veces son impuestos por la fuerza. En la actividad de compraventa de sexo se producen y circulan saberes sobre los grados de autonomía que se posee y sus límites; saberes sobre las técnicas a emplear y de las habilidades para hacer más efectiva la acción. También se aprende acerca de los modos de evasión de los controles internos al grupo y de los controles de la sociedad en su conjunto. De ahí que los acuerdos y pactos entre grupos sean frecuentes en la prostitución, lo que está relacionado con la menor o mayor amenaza que provenga del medio interno o externo al fenómeno social.

Simultáneamente, entre los individuos y grupos en prostitución y el resto de la sociedad existen múltiples relaciones e interacciones sociales, en ocasiones cara a cara e intencionales en ocasiones más impersonales e inconscientes. Esas relaciones han sido menos abordadas

4. ANGUITA, Concepción. El tráfico ilegal de seres humanos para la explotación sexual y laboral: la esclavitud del siglo XXI. Nómadas. Revista Crítica de Ciencias Sociales y Jurídicas 15(1): 3-16. España: Universidad Complutense de Madrid, 2007.

Revista de Ciencias Sociales - Número 69 (2016) - Universidad de Valparáíso - ISSN 0716-7725-Valparaíso, Chile 
por los investigadores sociales y por su envergadura requieren de un tratamiento independiente, el cual no pretendemos desarrollar en este trabajo. Sin embargo, es difícil pasar por alto una cuestión tan importante, de ahí que esbozaremos algunas ideas al respecto desde una mirada jurídico-social.

Por muy cerrados y subterráneos que se nos presenten los grupos en prostitución; entre las personas que a ellos pertenecen y el resto de la sociedad circula constantemente información, al punto que los llamados actores legos generalmente saben sobre la realidad de la prostitución; en algunos casos sin haber tenido contacto cara a cara con individuos dedicados a la compra venta del sexo.

Las vías por las que circula información pueden ser múltiples desde un amigo o amiga que sabe sobre la prostitución, vecinos que hablan lo mucho que conocen sobre el particular, la observación cotidiana, los medios de difusión, etc. Además, las personas que ejercen la prostitución, generalmente, poseen una familia, residen en alguna comunidad y entre ellos pueden establecerse múltiples relaciones que siguen diversos derroteros. Esas relaciones pueden ser contradictorias, no siempre conducentes a la segregación y a la estigmatización de las personas en prostitución pues en múltiples casos hemos observado actitudes y comportamientos ambivalentes hacia ellas. En algunas comunidades, especialmente aquellas que atraviesan por circunstancias nuevas y problemáticas, es posible que sus miembros dejen de percibir la prostitución como un problema, o al menos como su principal problema. También pudiera ocurrir que la compraventa de servicios sexuales comience a percibirse como un asunto privado o como una estrategia de vida válida y efectiva. Si lo anterior se conjuga con relaciones satisfactorias y de confianza entre sujetos en prostitución, familia y comunidad pudiera condicionar que emerjan y se refuercen actitudes, creencias y comportamientos favorables, anuentes hacia la prostitución. Esto último pudiera estar cruzado por el oportunismo de algunas personas; pero también pudiera obedecer no a alguna motivación directa sino a la rutinización de determinados esquemas comprensivos y prácticas respecto a la prostitución.

Los grados de presencia de las diversas relaciones sociales propias de la prostitución o generadas por esta; así como el tejido social que se

Facultad de Derecho y Ciencias Sociales - Universidad de Valparaíso - Chile 
produzca entre unas y otras varían de una sociedad a otra. Ello guarda relación con el grado en que la prostitución se haya establecido como fenómeno social en una sociedad, lo que a su vez deriva no sólo del tipo de legislación imperante o de la menor eficacia de las intervenciones legales y policiales, sino también, de otros factores de la prostitución.

La prostitución requiere para su funcionamiento de una base material como los modos de retribución de las prostitutas y prostitutos, las casas de citas, los hoteles, las calles, los burdeles, medios para comunicarse, etc. Es criterio de las autoras que la prostitución es un fenómeno heterogéneo, este carácter se revela, como ha dado cuenta Dorrais en sus estudios, que la presencia de mujeres y hombres de orientación sexual es diversa, entre los que dan el servicio sexual y sus clientes $^{5}$

Los que dan el servicio sexual son, generalmente, personas jóvenes, entre ellos se encuentran niños/as, adolescentes y adultos jóvenes; lo que no debe hacernos perder de vista la presencia de personas en edades más avanzadas en el fenómeno social. La heterogeneidad presente en la prostitución también se revela en la incidencia que tienen en el fenómeno social personas en situaciones socioeconómicas desfavorables y personas en situaciones socioeconómicas favorables. Si nos atenemos al nivel de instrucción de los prostitutos y prostitutas, su heterogeneidad puede ser más acentuada en unos contextos sociales que en otros; pero en la prostitución están presentes personas de diferente nivel de instrucción, desde las analfabetas y las que han abandonado los estudios en diferentes niveles de enseñanza ${ }^{6}$ al parecer predominantes entre los que dan el servicio sexual; hasta las/os que estudian y han concluido la universidad ${ }^{7}$.

En cuanto a la edad de los clientes de la prostitución la diversidad es mucho más acentuada pues en ellos están presentes personas de casi

5. DORAIS, Michel. Intimidad en venta: ¿cómo se llega a ser trabajador sexual? México: Red Desacatos, 2006. Obra referenciada.

6. HOWELL, Jayne. Las Lupes oaxaqueñas: obligaciones familiares y económicas. Editorial: Red Desacatos, 2006.

7. CHEJTER, Silvia. Obra referenciada.

Revista de Ciencias Sociales - Número 69 (2016) - Universidad de Valparáíso - ISSN 0716-7725-Valparaíso, Chile 
todas las edades: jóvenes, de la mediana y de la tercera edad. Recordemos que lo que todos ellos tienen en común es, básicamente, su disposición y capacidad de pagar. Además, en los clientes de la prostitución están representadas personas de todos los niveles de instrucción, clases y capas sociales. Las vías de entrada a la prostitución son diversas: muchas personas son obligadas mediante diversas formas de violencia ${ }^{8}$, pero otras deciden ser prostitutas. En lo referido a las formas de prostitución también encontramos la ausencia de homogeneidad pues existe una alta, media y baja prostitución, clasificación que da cuenta de las diferencias de estatus y poder de las personas prostitutas; lo cual tendría que ver con el origen étnico, presencia física y edad; los contactos, nivel de instrucción y recursos que se posean al momento de comenzar a ejercer la actividad; los espacios sociales en que se desenvuelven, los clientes que frecuentan, el valor monetario de sus servicios sexuales, ingresos acumulados, etc.

Situados en la oferta de prostitución se ha constatado la interrelación de la pobreza, con el incremento de mujeres madres y jefas de hogar, divorciadas y que emigran hacia áreas urbanas en busca de empleo; algunas lograron insertarse en actividades laborales escasamente remuneradas, otras no; y frente a ello decidieron ejercer la prostitución como medio complementario y en ocasiones único para lograr o incrementar los ingresos requeridos para la manutención de la familia9.

Se han verificado las interrelaciones dialécticas entre la pobreza, la deserción escolar, la crisis de valores, la violencia intrafamiliar, el incremento de los niños en la calle y de la calle con la prostitución forzada y voluntaria. Las investigaciones de Bermúdez, Gaviria y Fernández, entre otras ofrecen una mirada a diferentes formas de prostitución que involucran a personas de la clase media y alta, algunas con un alto nivel de instrucción ${ }^{10}$. Respecto a lo anterior, la lectura de la

8. ANGUITA, Concepción. Obra referenciada.

9. HOWELL, Jayne. Obra referenciada.

10. BERMÚDEZ, Ángela; GAVIRIA, Ana Milena; FERNÁNDEZ, Hamilton. Estilos psicológicos de la personalidad en un grupo de mujeres adultas jóvenes dedicadas a la prostitución "prepago” en la ciudad de Medellín. Chile: Red Terapia Psicológica, 2009.

Facultad de Derecho y Ciencias Sociales - Universidad de Valparaíso - Chile 
obra de dichos autores, entre otros, sugiere que en ello pueden influir factores asociados a procesos de una movilidad social vertical, descendente, estilos de vida consumistas, y adicciones, que requerirían de una cantidad considerable de recursos materiales; unido al fenómeno denominado padres ausentes, especialmente en una edad complicada como la adolescencia. En vínculo con lo antes dicho habría que considerar la incidencia que en la prostitución ejercen las necesidades sociales, con toda la complejidad que ello contiene. Es posible pensar, anclados en el carácter paradójico y negociable de dichas necesidades, que la búsqueda de estatus y poder juega un papel no despreciable en la entrada de sujetos diversos en la prostitución. Un factor que influye en la prostitución a saber es la demanda de este acto, la cual Lamo de Espinosa relaciona con procesos de desequilibrio demográfico o social entre los sexos, que generarían determinado número de personas con dificultades temporales o permanentes de encontrar pareja estable, algunos de los cuales recurrirían a la compra de servicios sexuales para acceder, con fines eróticos, al sexo opuesto ${ }^{11} \mathrm{o}$ al sexo que se prefiere.

Las autoras se afilian a la idea de Lamo de Espinosa de que esa demanda pudiera crecer bajo la influencia de matrimonios insatisfactorios; pero otros autores consideran, acertadamente, con base en hallazgos empíricos, que pueden darse casos de personas con matrimonios satisfactorios que consumen servicios sexuales, dado la amplia confluencia de la diversión, el ocio y el sexo, unido a creencias y actitudes culturalmente configuradas sobre la prostitución ${ }^{12}$.

Otros factores no menos significativos tienen la potencialidad de ejercer regulación sobre el fenómeno social, o sea, propiciar su aumento o disminución. Entre los factores hemos considerado los grados de anuencia o censura grupal hacia la prostitución; las opiniones, creencias, actitudes y comportamientos hacia el fenómeno social, la

11. LAMO de ESPINOSA, Emilio. Delitos sin víctima. Orden Social y Ambivalencia moral. Madrid, Alianza Editorial, 1993.

12. SAWYER, Steven y otros. Attitudes Towards Prostitution Among Males: A 'Consumers' Report'. Current Psychology, 10461310, Winter 2001, Vol. 20, Fascículo 4.

Revista de Ciencias Sociales - Número 69 (2016) - Universidad de Valparáíso - ISSN 0716-7725-Valparaíso, Chile 
moralidad sexual, el ethos cultural hegemónico, la conversión o no de los grupos en prostitución en grupos de referencia para algunas personas, las redes sociales que se establecen entre los individuos y grupos en prostitución y el resto de la sociedad, los individuos, los grupos, la familia, la comunidad; la existencia o no de procesos de rutinización y naturalización de esquemas comprensivos y prácticas respecto a la prostitución; el grado de institucionalización de la prostitución, inseguridad ontológica sostenida; reacciones adaptativas de los individuos y grupos a su sociedad y cultura; situaciones socioeconómicas desfavorables sostenidas; entornos comunitarios adversos, procesos de crisis societal profunda y larga duración temporal, entre otros.

Todo lo antes referido sugiere, desde ya, que un estudio acerca de las causas de la prostitución debe tomar distancia de las simplificaciones causales. Estamos en presencia de un fenómeno complejo y multifactorial, del cual no podemos dar cuenta a partir de la sumatoria de causas más o menos relacionadas.

La existencia de este fenómeno social es resultante de complejas interacciones entre factores socioeconómicos, demográficos, culturales, políticos, jurídicos, sociopsicológicas, entre otros, con cabida a la retroacción del propio fenómeno social sobre los factores que sobre él inciden. La reflexión anterior supone un intento explícito de tomar distancia del modelo de causalidad mecanicista, lineal, reduccionista, a favor de un modelo de causalidad dialéctico no lineal.

Para comprender y hacer comprensible los factores que pueden incidir en la prostitución, nos situamos en algunos de los reguladores jurídicos y sociales. En tal sentido asumimos, con Giddens, que el comportamiento humano puede ser regulado por el Estado, las leyes vigentes, y normativas propias de las variadas organizaciones, instituciones y grupos sociales. Sin embargo, dado el carácter activo del sujeto, sus acciones se regulan también por la conveniencia económica, la sensatez, la racionalidad, la eficacia del comportamiento social, y por procesos de autorregulación reflexiva.

Múltiples aspectos de la vida social como los valores, el lenguaje, los conocimientos, las actitudes, entre otros; contienen, y funcionan como reglas implícitas para el comportamiento social, en tanto inseparables de los procesos de constitución de sentido subjetivo y sirven

Facultad de Derecho y Ciencias Sociales - Universidad de Valparaíso - Chile 
de referencia para la actuación de unos sujetos hacia otros. Por supuesto, las reglas referidas a la constitución de sentido subjetivo y las que legalmente sancionan los modos de comportamiento social, son inseparables de los grupos e instituciones de los cuales se forma parte o por alguna razón se toman como referencia; en los que se expresan las condiciones objetivas y subjetivas de su aplicación.

Un intento de acercamiento sociológico a los factores de la prostitución es considerar que sus interacciones ocurren en un contexto social, en un momento dado, bajo circunstancias concretas que en conjunto denominamos condiciones específicas de existencia social donde deviene el fenómeno en estudio y adquiere una especificidad cualitativa que le confiere su identidad concreta. Por lo que podemos hablar de los factores de la prostitución en condiciones de crisis, de cambio social, de relativa estabilidad, etc. Al enfocar los factores de la prostitución podemos situarnos en diferentes niveles de análisis de la realidad social, siendo estos: nacionales, regionales, comunitarios y globales; así como en lo social, lo grupal y lo individual. También podemos situarnos en diferentes planos: interno y externo. Sin embargo, debemos sortear posiciones deterministas a la hora de considerar algunos de los factores, niveles y planos considerados y adentrarnos en las interrelaciones complejas existentes entre ellos.

\section{Análisis histórico-jurídico-social de la prostitución en Cuba}

La literatura producida desde los estudios históricos, haya sido o no la prostitución su objeto de estudio, es inestimable para comprender las singularidades lógicas e históricas de la prostitución en la sociedad cubana. Estas singularidades se deben, en un sentido amplio, primero a las circunstancias propias de una sociedad colonial, a la cual se le impusieron, paulatinamente, instituciones, prácticas y normas legales dominantes en la Metrópoli ${ }^{13}$, lo cual, sin dudas, generó fuentes múltiples de ambivalencia y contradictoriedad social.

13. VERA, Ana, Estudiar la Familia. Un repaso. Temas \# 31: 101-110, octubrediciembre de 2002.

Revista de Ciencias Sociales - Número 69 (2016) - Universidad de Valparáíso - ISSN 0716-7725-Valparaíso, Chile 
En la sociedad colonial, las constricciones sociales ejercidas por la normatividad respecto al matrimonio, la familia y la sexualidad se debilitaron; especialmente por la existencia de un sistema de estratificación social que obró en sentido contrario a la normatividad social. En este sentido, la posición, en el sistema de estratificación social, de las personas negras esclavas y de las negras y mulatas libres - mayoría en la población cubana, desde, aproximadamente, 1817 hasta mediados del siglo XIX ${ }^{14}$ — conduce a que muchas de ellas, frente a las adversidades de su vida cotidiana, en una especie de dialéctica del control social, intentaran tomar las riendas de su vida, a través de la prostitución. Esto no significa que la prostitución haya sido el único camino para las negras y mulatas libres. De hecho, en la sociedad colonial, especialmente desde fines del siglo XVIII las negras y mulatas libres... "se movían constantemente por la ciudad, contribuyendo activamente a su economía y participando dinámicamente en su vida social. Ellas constituían la mayoría de las vendedoras, artesanas, parteras, sirvientas, cuidadoras y maestras de primeras letras. Algunas eran dueñas de negocios o prestamistas" 15 .

$\mathrm{Al}$ mismo tiempo, es lógico que la prostitución de mujeres negras y mestizas, en condiciones de pobreza extrema, exclusión y marginalidad, - fenómeno que se agravará por la situación de vulnerabilidad en que quedan luego de la eliminación de la esclavitud; situación que se mantuvo mayoritaria, en cifras absolutas, hasta bien avanzado el siglo $\mathrm{XIX}^{16}$. En el caso de las esclavas en prostitución, su sujeción legal a los dueños, hasta 1886, implicó que tenían la anuencia, autorización o habían sido presionadas por los mismos. Sobre esto último se asegura que muchos hacendados les autorizaban a vender sus cuerpos en tabernas y posadas; lo que revela la existencia de representaciones y

14. Ibídem.

15. MENA, Luz M. Raza, género y espacio: las mujeres negras y mulatas negocian su lugar en La Habana durante la década de 1830. Colombia: Red Revista de Estudios Sociales, 2009: 10 http://site.ebrary.com/lib/vepingsp/Doc? id=10306750

16. ELIZALDE, Rosa M. Flores desechables. ¿Prostitución en Cuba? Editora Abril, Cuba. 1996.

Facultad de Derecho y Ciencias Sociales - Universidad de Valparaíso - Chile 
prácticas oscilantes que se reproducirán a lo largo de la colonia; una cosa era la madre-esposa de clase media y alta, guardiana del hogar y otra muy diferente era la mujer esclava y además negra, rebajada a la condición de instrumento ${ }^{17}$. Cabe aclarar que, en las circunstancias de la sociedad colonial, la capacidad reguladora de la ambivalente moral sexual católica tiende a debilitarse, porque ella oscila entre una definición de la prostitución como inmoralidad y una definición como mal necesario; y también porque los códigos sociales que regían el comportamiento sexual de las mujeres blancas de altos estratos, tuvieron una menor influencia sobre la mayoría de las mujeres negras y mulatas libres ${ }^{18}$.

Un aspecto resaltado por algunos investigadores es las limitaciones a la libre empresa, en las difíciles condiciones socioeconómicas de la colonia; incluso, para algunos en posiciones relativamente más ventajosas en el sistema de estratificación social. Ello condujo a que algunos hacendados buscaron formas alternativas para incrementar sus ingresos, entre ellas, el fomento de la prostitución ${ }^{19}$; lo que pone de manifiesto la influencia de la conveniencia económica de dichos sujetos en este fenómeno social.

$\mathrm{Al}$ mismo tiempo, el negocio del sexo, tiende a florecer en la sociedad cubana colonial bajo la influencia de una demanda de prostitución por parte de comerciantes, soldados, contrabandistas, algunos clérigos y frailes, entre otros. La demanda de prostitución se acelera con el incremento de un población flotante, generada por el desarrollo del comercio de contrabando; la creación definitiva del sistema de flotas, a partir de la segunda mitad del siglo XVI y la conversión del puerto de La Habana en el principal puerto del continente; y tras la revolución haitiana en 1772, la transformación de Cuba en capital azucarera del mundo ${ }^{20}$ Evidentemente, la prostitución

17. LOYOLA VEGA, O., La sociedad insular. En: Cuba y su historia, Editorial Félix Varela, La Habana, 2005: 23.

18. MENA, Luz, Obra referenciada.

19. ELIZALDE, R. M, obra referenciada.

20. LOYOLA, 2005, obra referenciada.

Revista de Ciencias Sociales - Número 69 (2016) - Universidad de Valparáíso - ISSN 0716-7725-Valparaíso, Chile 
alcanzó más auge en aquellos espacios sociales de mayor avance económico, trata negrera, crecimiento poblacional y desequilibrio demográfico.

La crisis vivida en la década del 60 del siglo XIX y las consecuencias de las guerras de 1868-1878 y $1895-1898^{21}$, agravadas en la Guerra iniciada en 1895, por los efectos del bloqueo naval y el periodo de reconcentración, provocaron un crecimiento abrupto de la prostitución por razones de pobreza extrema, exclusión y marginalidad en toda la sociedad cubana ${ }^{22}$. Dado lo anterior es entendible que se produjeran cambios en la procedencia social y la composición racial de las mujeres en prostitución: las mujeres blancas, de origen campesino, se han constatado como mayoría entre las prostitutas, a fines del siglo XIX. Los cambios en la composición social y racial de la prostitución en esta fecha son los siguientes: Antes de 1868, negras y mulatas (80\%); españolas (12\%); campesinas cubanas pobres (6\%); otras, chinas, árabes, americanas (2\%). De 1879 al 1895: negras y mulatas (35\%); campesinas y cubanas pobres (47\%); españolas (3\%), otras (15\%), distribuidas en más de 1300 casas de tolerancia, en todo el país ${ }^{23}$.

También tendríamos que tener en cuenta que hacia 1887 la población de color blanco casi había duplicado numéricamente a la población de negros y mulatos. Hacia 1862, la población cubana era de 1.359.238 habitantes; de ellos, blancos (764.750), negros y mulatos libres (221.417), esclavos (373.071). Hacia 1887, en una población total de 1.609.075, eran blancos (1.080.277), negros y mulatos libres $528.798^{24}$. Estos últimos, sin embargo, aportaban aún el $35 \%$ de los personas en prostitución; de modo que, en cifras relativas, seguían siendo, quizás,

21. IZQUIERDO CANOSA, R., La reconcentración. 1896-1897, Ediciones Verde Olivo, La Habana, 1997; VERA, Ana. Estudiar la Familia. Un repaso. Temas No 31: 101-110, octubre-diciembre de 2002; BARCIA ZEQUEIRA, M. C. Una sociedad en Crisis: La Habana a finales del sigo XIX. Editorial de Ciencias Sociales, La Habana, 2009.

22. BARCIA ZEQUEIRA, M. C. Ibídem.

23. FIGUERAS, F., 1907: 284/ Elizalde, R. M., 1996: 32.

24. LOYOLA, Oscar. obra referenciada. 
el grupo que más aportaba a la prostitución y el que estaba expuesto a peores condiciones por la confluencia de la pobreza y los prejuicios raciales.

El color de la piel o la procedencia social y geográfica no fueron los únicos factores diferenciadores de las prostitutas. Según Barcia Zequeira, en 1889, el 32,4\% de las prostitutas... "trabajaban en los servicios o tenían alguna profesión. La mayor parte estaba constituida por criadas de manos, lavanderas, planchadoras, costureras y tabaqueras". Otras lograron tener un alto nivel de vida, que les permitió agenciarse un trato diferenciado en algunos establecimientos públicos, incluso en el convulso año de $1898^{25}$.

Un factor no despreciable en el análisis de los factores que pueden haber contribuido a la ampliación de la prostitución, en determinados espacios sociales, a finales del siglo XIX, es la normatividad legal respecto a la prostitución, en vigor a partir de 1873, que en esencia sigue un modelo reglamentarista; el cual desplazó y concentró las áreas permisibles para ejercer la prostitución hacia barrios marginales, donde vivía una población trabajadora o desocupada muy pobre; por ejemplo el conocido barrio habanero de San Isidro, que favoreció determinada tolerancia social hacia la prostitución ${ }^{26}$. Los cambios en el contexto social, iniciados en las últimas décadas del siglo XIX y acelerados durante la neocolonia (1902-1958), fundamentalmente el tránsito hacia estructuras capitalistas, dependientes del capitalismo estadounidense, propiciaron condiciones óptimas para la conversión de Cuba en el llamado Prostíbulo de América, término que refiere las dimensiones que adquirió la prostitución, en la etapa, al consolidarse como negocio organizado y sus vínculos con el negocio de las drogas y los juegos.

En las circunstancias de un capitalismo deformado y dependiente, se estructuró un sistema de estratificación social, con base en las asimetrías étnicas, entre clases sociales, los géneros, entre otras, que contribuyó al despliegue de la prostitución. Según las diversas investigaciones, la prostitución se nutrió, en este periodo, fundamentalmente,

25. BARCIA ZEQUEIRA, M. C. Ibídem. Pp. 118-119.

26. Ibídem.

Revista de Ciencias Sociales - Número 69 (2016) - Universidad de Valparáíso - ISSN 0716-7725-Valparaíso, Chile 
de mujeres de escaso nivel de instrucción, desempleadas, pobres y en un gran número provenientes de zonas rurales. El modelo de capitalismo imperante expuso a la sociedad cubana a los vaivenes del mercado internacional y de la economía norteamericana. Ello tuvo implicaciones sociales de naturaleza negativa que alcanzaron su clímax en periodos de crisis $^{27}$.

Así sucedió, por ejemplo, tras los efectos de las crisis de 1920 a 1921 y de 1929 al 1933. Las mismas conmocionaron una sociedad de población creciente, de altos índices de analfabetismo, desempleo y pobreza. La agricultura y los servicios, que exigían una baja calificación, además, eran las principales opciones de empleo para hombres y mujeres, respectivamente. Situación que se mantendrá, con ligeras variaciones hacia finales de los años 50 del siglo $\mathrm{XX}^{28}$. En cada crisis se incrementó el número de desocupados y se agravó la situación de los salarios, deprimidos por la competencia de obreros extranjeros, especialmente antillanos. En esta situación numerosas personas, entre ellas las mujeres, emigraron del campo a las ciudades y sin educación, ni formación profesional muchos engrosan los barrios marginales, y otras recurrieron a la prostitución, o quedaron atrapadas en sus redes. Las normas jurídicas aprobadas durante la neocolonia, por su parte, refuerzan la pervivencia de la prostitución en determinados espacios sociales y con ello el vínculo entre pobreza, marginalidad y prostitución. Hacia 1913, se reglamenta jurídicamente la prostitución, dándose continuidad a toda una tradición legal que proviene de la colonia. En los años 20 y 30 del sigo XX se aprobaron algunas normativas legales respecto a la prostitución ${ }^{29}$. En su análisis al respecto Sandra Mustelier destaca el Decreto-Ley No 384 del 2 de noviembre de 1925, referido a la trata de blancas y está acompañado de un nuevo reglamento de inmi-

27. LÓPEZ CIVEIRA, F., “La República (1899-1959)”. En: López Civeira, F.; Loyola O.; Silva L. "Cuba y su Historia. Editorial Félix Varela. La Habana, 2005. Pp. 117-216.

28. Ibídem.

29. MUSTELIER CARMENATY, Sandra. La prostitución desde el Derecho, 2002. Mimeo.

Facultad de Derecho y Ciencias Sociales - Universidad de Valparaíso - Chile 
gración que establece el castigo con prisión correccional a quien directa o indirectamente transporte a Cuba mujeres para dedicarse a la prostitución.

En 1936 entra en vigor el Código de Defensa Social mediante el Decreto Ley 802 de 1936; en su capítulo 7 se preceptúa todo lo relativo al estado peligroso y los índices de peligrosidad permanente, para aquellas personas que incurrieran en el ejercicio de la prostitución en menores, imponiéndose en ese caso la medida de seguridad consistente en asignación a una colonia agrícola o taller o casa de trabajo del gobierno. Los referidos Decretos Ley no desmontaron el tratamiento jurídico reglamentarista existente hasta la fecha y fueron una respuesta obligada a la creciente opinión pública, dentro y fuera de Cuba, para que se tomaran medidas contra la prostitución infantil, el proxenetismo y la llamada trata de blancas ${ }^{30}$.

Análisis de la prostitución en el periodo de 1959-actualidad. La revolución en el poder

El triunfo de la revolución cubana en 1959, abrió un proceso de profundas transformaciones que conmovieron las bases de la prostitución. En este sentido, es indudable, la influencia ejercida por la eliminación de las relaciones de explotación basadas en la propiedad privada, la disminución de las asimetrías socioeconómicas; el proceso de urbanización, el acceso masivo de hombres y mujeres a la educación, al empleo urbano y a la participación sociopolítica, al propiciar una elevada movilidad social ascendente ${ }^{31}$. Simultáneamente, se encauzó un conjunto de medidas específicas para erradicar la prostitución. Entre esas medidas se procedió al cierre de burdeles y a la reinserción social de las mujeres prostitutas, a través del trabajo, el estudio, la atención a sus hijos, entre otras. Para las que continuaran ejerciendo la prostitución se dispuso su internamiento en granjas agrícolas o en otras instituciones,

30. Ibídem.

31. ESPINA, M., MARTÍN, L., y NÚÑEZ, L., 2001. Reajuste económico y cambios socioestructurales. En: Revista Temas. 3ra época número 21-2001.

Revista de Ciencias Sociales - Número 69 (2016) - Universidad de Valparaíso - ISSN 0716-7725-Valparaíso, Chile 
luego de lo cual, en 1965, se declaró la erradicación de la prostitución.

No obstante observarse algunas manifestaciones individuales de compra-venta de servicios sexuales esporádicos a lo largo de los años en algunas comunidades, e incluso un ligero repunte durante la crisis económica de inicios de la década 1970 y alrededor de los puertos en la siguiente década ${ }^{32}$, la prostitución no se institucionalizó oficialmente, o sea no cristaliza como problema social. Las manifestaciones individuales de compra-venta de servicios sexuales, evidenciaban que la problemática social se mantuvo latente; y con todo, ello se atribuyó más a remanentes del pasado y menos a la influencia de otros factores sociales generados por el contexto social. De hecho, la prostitución se convirtió en un tema tabú; hasta que a mediados de la década de 1990, paulatinamente diferentes estudios comenzaron a dar cuenta del fenómeno social en las circunstancias multicausal y multidimensional crisis.

Lo antes dicho no significa que el poder político se mantuviera al margen de lo que estaba ocurriendo; muestra de ello es la posición abolicionista que mantiene la revolución cubana, en lo que respecta a la prostitución. Dicha posición abolicionista se evidencia en el discurso político, en la práctica oficial de las instituciones y organizaciones del sistema político cubano, y en la prioridad otorgada a la prevención y enfrentamiento a la problemática social.

En el discurso político, se reconoce la envergadura que había alcanzado el fenómeno social y sus nexos con algunas formas de delito. Por ejemplo, el Discurso pronunciado por Fidel Castro el 5 de enero de 1999, se dedica un espacio al análisis de una información del Ministerio del Interior, titulada: "Prostitución y proxenetismo", donde se afirmaba que: "Este fenómeno delictivo, que afecta fundamentalmente a los polos turísticos del país, mantiene una tendencia creciente. Se aprecian algunos niveles de organización y de vínculos con otras tipicidades delictivas graves, tales como la droga, el contrabando, la corrupción de menores y el delito contra extranjeros".

Los resultados fundamentales en este enfrentamiento se concretan, hasta el cierre de noviembre de 1998, en: "La presentación a los

32. Ibídem.

Facultad de Derecho y Ciencias Sociales - Universidad de Valparaíso - Chile 
tribunales, a nivel nacional, de 157 expedientes de fase preparatoria por proxenetismo, con 219 acusados, de los que han resultado sancionados 190 de 219; al 56\% les fue impuesta la sanción de privación de libertad". A la vez que se alude a un conjunto de acciones oficiales para desestimular el crecimiento de la prostitución, mediante la aplicación del índice de peligrosidad social predelictivo a las personas que entregan el servicio sexual. Al respecto, en dicho discurso se plantea que "De acuerdo con la ley, por reincidencia y reiterada conducta antisocial, hablando en este caso de la prostitución, 277 fueron internadas en centros de rehabilitación; las restantes han sido advertidas y devueltas a sus lugares de residencia. Aquí la cifra resulta más bien baja, porque, según el informe: "El centro de recepción, clasificación y procesamiento de prostitutas de Ciudad de La Habana recibió, hasta noviembre de 1998, 6.714 mujeres, equivalentes a un promedio de 610 mensuales. El $59 \%$ proceden del interior del país”. Así que tenemos una elevada prostitución inmigrante en la capital. Parecen pocas, pero el ministerio va creando las condiciones para que aquellas que realmente resulten reincidentes y de reiterada conducta antisocial, y sean internadas en centros de rehabilitación" 33 .

Es menester aclarar que en lo que respecta a la prostitución en Cuba, legalmente la entrega directa del servicio sexual no está tipificado como un delito, sino como un estado peligroso. En tal sentido, acorde al vigente Código Penal la actual Ley No 62 de 1987, actualizada en 1997, las personas en prostitución o más bien las que brindan directamente el servicio sexual a cambio de dinero u otro bien, son consideradas personas en estado peligroso, — en su acepción de vicios socialmente reprobables por la sociedad-, que de comprobarse en el correspondiente proceso, conllevaría a medidas de seguridad predelictivas y reeducativas. Según el vigente Código Penal Cubano, el estado peligroso de una persona se define por su especial proclividad para cometer delitos, sin llegar a constituir un delito, demostrado por una

33. Discurso pronunciado por el presidente Fidel Castro Ruz en el acto por el aniversario 40 de la constitución de la Policía Nacional Revolucionaria, efectuado en el teatro Carlos Marx, 5 de enero de 1999, Año del 40 aniversario del triunfo de la Revolución. Granma Internacional Digital. La Habana. Cuba.

Revista de Ciencias Sociales - Número 69 (2016) - Universidad de Valparáíso - ISSN 0716-7725-Valparaíso, Chile 
conducta que sigue en contradicción manifiesta con las normas de la moral socialista. Las medidas reeducativas se aplican a individuos antisociales, y su término es de un año como mínimo y de cuatro años como máximo. Entre tales medidas se encuentran: internamiento en un establecimiento especializado de trabajo o de estudio; entrega a un colectivo de trabajo para el control y la orientación de la conducta del sujeto en estado peligroso.

Se establece la vigilancia mediante la orientación y el control de la conducta del sujeto en estado peligroso, por los órganos de la Policial Nacional Revolucionaria. Para aquellos que no clasifican en lo conceptuado como estado peligroso, pero tienen vínculos con personas potencialmente peligrosas, se establece que serán objeto de advertencia oficial, como medida preventiva ${ }^{34}$. En el Código Penal cubano, el proxenetismo, la trata de personas, la pornografía y la corrupción de menores, son considerados delitos contra el normal desarrollo de las relaciones sexuales y contra la familia, la infancia y la juventud; y se establecen severas sanciones principales de privación de libertad y accesorias, para los sujetos que incurran en dichos delitos.

El Código Penal cubano, en el TÍTULO XI, norma los delitos contra el normal desarrollo de las relaciones sexuales y contra la familia, la infancia y la juventud. En el Capítulo I en su sección cuarta, aparecen regulados los delitos contra el normal desarrollo de las relaciones sexuales. Lo concerniente a la pornografía aparece en la sección quinta, el ultraje sexual, en los incisos b y c de dicho Capítulo. En el Capítulo III, del referido TÍTULO, denominado Delitos contra el normal desarrollo de la infancia y la Juventud, en la Sección Primera, se regula lo referido a la corrupción de menores, y lo que corresponde como parte de ello a la problemática de la prostitución en los artículos 310 , 311, 314. Durante el año 2012 en Cuba existía una población total de 2.260.751 personas hasta 16 años de vida (que marca la mayoría de edad civil en nuestro país ), se registraron denuncias que involucraron como víctima a niños y niñas, equivalente a un 0,09 por ciento de la

34. Ley No 62 de 1987, vigente Código Penal, Libro I. Título XI. El Estado Peligroso y las medidas de seguridad, Artículo 72; 73, c., 2; 75; 76; 77. Ministerio de Justicia, 1997.

Facultad de Derecho y Ciencias Sociales - Universidad de Valparaíso - Chile 
población infantil, lo cual, si tenemos en cuenta la alta prioridad al cuidado de los niños y niñas y la alta repulsa social a todo comportamiento que involucre abuso sexual a niños y niñas que deriva, al conocerse, en denuncias de la población, demuestran que los hechos de abuso sexual contra niños y niñas mantuvieron niveles ínfimos ${ }^{35}$. En el quinto informe nacional sobre el enfrentamiento jurídico penal a la trata de personas y otras formas de abuso sexual, presentado el 15 de octubre de 2013, por María Esther Reus, ministra de Justicia, se ratifica que desde el inicio de la revolución se implementaron programas de dignificación a las mujeres, niñas y niños, y se estructuró el ordenamiento jurídico e institucional para ello. El apego de Cuba a los principales instrumentos jurídicos internacionales sobre la trata de personas y otras formas de abuso sexual, la continuidad de una política de tolerancia cero a la trata de personas y en particular, al abuso sexual contra mujeres, niños, niñas y adolescentes, —a lo cual se suma un alto grado de rechazo de la población cubana a conductas que involucran a niños y niñas-; y de la prioridad asignada a la prevención y enfrentamiento de la prostitución en cualquiera de su formas.

Cuba constituye un Estado signatario, es decir ha suscrito y ratificado los principales Instrumentos Internacionales sobre la trata de personas y otras formas de abuso sexual, como el protocolo para prevenir, reprimir, y sancionar la trata de personas, especialmente de mujeres y niños. Sostiene 53 acuerdos bilaterales de asistencia judicial, entre ellos 23 de asistencia jurídica en materia penal, 19 sobre traslado de sancionados y 11 de extradición. El país está integrado a la Red Iberoamericana de Cooperación Judicial Internacional, que facilita el intercambio de datos e informaciones sobre casos penales y civiles en trámite. Como parte de la cooperación con servicios policiales extranjeros y la Interpol, el Ministerio del Interior cubano brinda seguimiento y control a las personas identificadas o que son objeto de búsqueda internacional por vincularse a la pedofilia, el proxenetismo u otros delitos

35. REUS, María Esther. "Quinto informe nacional sobre el enfrentamiento jurídico penal a la trata de personas y otras formas de abuso sexual, 15 de octubre de 2013, disponible en el sitio web del Ministerio de Relaciones Exteriores www.cubaminrex.cu

Revista de Ciencias Sociales - Número 69 (2016) - Universidad de Valparáíso - ISSN 0716-7725-Valparaíso, Chile 
sexuales, en especial a aquellos que afecten a menores de edad. Según la Ministra de Justicia, también hay colaboración con Canadá — principal emisor de turismo a Cuba-, Reino Unido y otros países ${ }^{36}$.

En la presente investigación como en otras realizadas por autores cubanos se ha verificado que la mayoría de los hechos de prostitución enfrentados no califican como trata de personas. Este es un fenómeno de una mínima presencia en la sociedad cubana; si lo comparamos con el alto registro policial que este delito presenta en otras sociedades. Según la ministra de Justicia, en el año 2012, 241 personas fueron juzgadas por el delito de proxenetismo. Siete extranjeros privados de libertad por el delito de corrupción de menores. Procesadas y sancionadas 14 personas, en nueve casos, donde se observaron conductas definidas como delito de trata de personas. Sobre lo último en la causa 276 de 2012 (sentencia No 373 de 2012), por ejemplo, versó sobre el proxenetismo. El sancionado a 15 años de privación de libertad, facilitaba contactos con extranjeros a una prostituta a cambio de dinero. En una oportunidad en que la víctima no pudo cumplir con la entrega porque el cliente no efectuó el pago, el sancionado la amenazó con asesinarla a ella o a sus hijos. En la causa 141 de 2011 (sentencia No 73 de 2012) se procesó a tres personas por el delito de corrupción de menores ${ }^{37}$. Cabe enfatizar que desde el punto vista jurídico y social en todo hecho en el que sean utilizados o afectados (de forma involuntaria, violenta, u otra forma coactiva) niños, niñas o adolescentes y jóvenes, el pueblo cubano reacciona con un alto grado de rechazo. Por consiguiente existe una alta tendencia a denunciar tales actos.

Es inexistente la explotación sexual de adultos, niños y niñas asociada a redes criminales que los mantengan en condiciones de semiesclavitud. Cuba, no constituye un país de origen, tránsito o destino de la trata de personas, los que constituyen realidades de amplia connotación en otras sociedades. Los delitos y comportamientos relativos

36. Ibídem.

37. REUS, María Esther. "Quinto informe nacional sobre el enfrentamiento jurídico penal a la trata de personas y otras formas de abuso sexual, 15 de octubre de 2013, disponible en el sitio web del Ministerio de Relaciones Exteriores www.cubaminrex.cu

Facultad de Derecho y Ciencias Sociales - Universidad de Valparaíso - Chile 
a la prostitución son asumidos con políticas de prevención y enfrentamiento a partir de un sistema integrado de instituciones y organizaciones de la sociedad civil.

La Federación de Mujeres Cubanas (FMC), por ejemplo, dispone de 173 casas de orientación a la mujer y a la familia, con un protagonismo en la igualdad de derechos y género. En el sistema educacional se aplica un programa de educación sexual con fuerte componente ético y en la formación de valores para prevenir el ejercicio de la prostitución. El Ministerio del Turismo (MINTUR) en Cuba aplica medidas para impedir la promoción del turismo de sexo y la prostitución en sus instalaciones y conmina a las contrapartes extranjeras a observar estas regulaciones, al tiempo que se potencia como política el turismo familiar, para lo cual se estableció la estancia gratuita de los menores de 12 años de edad. Respecto a las mujeres en prostitución, la Ministra de Justicia manifiesta acertadamente la labor de persuasión y convencimiento que se ejerce sobre ellas, y la búsqueda de las causas que originan su entrada a tal tipo de actividad, para tratar de suprimirlas. En tal sentido, se canalizan las necesidades de empleo, la incorporación al estudio y otras alternativas, al tiempo que se potencia el rechazo social a la figura del proxeneta y se protege a las víctimas ${ }^{38}$.

El Estado cubano pone en práctica un conjunto de medidas de seguridad reeducativas de internamiento de las mujeres aseguradas por ejercer la prostitución. Se trata de que las aseguradas eleven su nivel educacional y cultura general, así como se formen en valores positivos en el orden ético, estético y moral que propicie su reincorporación a la sociedad. La ejecución de las medidas antes expuestas se llevan a cabo dentro de los principios de la legalidad y la moral socialista, excluyéndose todo tipo de medidas que puedan causar sufrimientos físicos o psíquicos o que humillen la dignidad humana.

Sin embargo, es una realidad que la aplicación del índice de peligrosidad social predelictivo ha recaído fundamentalmente sobre las mujeres en prostitución. Las autoras han verificado en otras regiones del país, algunos hallazgos de la investigación realizada por Sandra Mustelier entre los años 1999 y 2002 en Santiago de Cuba. La misma

38. Ibídem.

Revista de Ciencias Sociales - Número 69 (2016) - Universidad de Valparáíso - ISSN 0716-7725-Valparaíso, Chile 
demostró que en ese periodo ningún hombre había sido procesado por ejercer la prostitución, aún cuando se reconocía su existencia; pero, generalmente, se identificaba la prostitución masculina con la homosexualidad o con el proxenetismo. Al mismo tiempo, se observó determinada resistencia a reconocer la existencia de la prostitución masculina heterosexual ${ }^{39}$.

A casi 20 años del discurso de Fidel Castro, dentro de las acciones oficiales llevadas a cabo a nivel de país se incluyen la detección, seguimiento y atención priorizada a las personas en prostitución o proclives a incurrir en tal práctica; así como el enfrentamiento al proxenetismo y la trata de personas, fomentar una cultura de rechazo a la prostitución en cualquiera de sus formas, entre otras que involucran a numerosos organismos, organizaciones e instituciones de la sociedad cubana. Los logros obtenidos han sido de gran relevancia; sin que pueda decirse que la prostitución haya dejado de ser un problema presente en la sociedad cubana. Pese a que la prostitución no alcanza en Cuba, la profundidad, connotación y formas más deshumanizantes observables en otras sociedades, diversos factores, a lo largo de los últimos años, inciden en su reproducción. En este sentido, se reconoce que en la ampliación del fenómeno social a partir de fines del pasado siglo, han incidido factores económicos; especialmente, el deterioro de las condiciones de vida en el marco de la crisis económica; ya sea por su impacto en la reducción de los ingresos ${ }^{40}$; en la disminución de las importaciones, lo que afectó las fuentes de energía, la entrada de productos alimentarios y de los recursos necesarios para un adecuado funcionamiento de los diversos servicios ${ }^{41}$.

Otros autores ${ }^{42}$, exponen como factores de la prostitución el incremento del desempleo, el subempleo, la economía sumergida, la

39. MUSTELIER CARMENATY, Sandra. La prostitución desde el Derecho, 2002. Mimeo.

40. Ibídem.

41. Ibídem.

42. MARTÍN FERNÁNDEZ, C., PERERA PÉREZ, M., DÍAZ PÉREZ, M. Introducción al estudio de la Vida Cotidiana desde la Psicología Social. En: Psicología Social y Vida Cotidiana. Selección de Lecturas. Primera parte. Editorial Félix Varela. La Habana, 2004.

Facultad de Derecho y Ciencias Sociales - Universidad de Valparaíso - Chile 
inversión de la pirámide de ingresos, la reducción de las posibilidades de la mujer para incorporarse al trabajo, el deterioro de las condiciones de vida de numerosas familias, se convirtieron en fuente de insatisfacción social y del crecimiento de las transgresiones de las normas morales y jurídicas. Las autoras son del criterio que la prostitución es un fenómeno multifactorial de carácter alineal y heterogéneo. Ello se exterioriza en la sociedad cubana, tanto en la no presencia en el fenómeno social de personas en similares situaciones socioeconómicas y culturales de las que sí están; como en la presencia de personas blancas y no blancas; hombres y mujeres que residen en territorios más avanzados y más retrasados, en situaciones socioeconómicas y culturales desfavorables; y también de algunas que viven en entornos comunitarios favorables, pertenecen a familias con una buena situación socioeconómica, estudian o trabajan, tienen un nivel de instrucción por encima de la media nacional, y de calificación más bien alto, con ingresos elevados, incluido en ocasiones el acceso frecuente a remesas de familiares en el exterior.

También están representados los diferentes tipos de familia, migrantes y no migrantes, aunque se observe una sobrerrepresentación, —no pocas veces por ser más visibles y estar más expuestos al control oficial-, de las negras y mestizas, o al menos en peores condiciones de partida al momento de entrar a la prostitución, de las mujeres, de migrantes vulnerables de territorios más deprimidos, y en general de los segmentos sociales en situaciones más desventajosas. Las autoras consideran que todos los factores inciden, condicionan, la existencia del fenómeno social y no que lleven ineluctablemente a ello; a excepción de los casos de personas que son obligadas, mediante la violencia a entrar y permanecer en prostitución (lo cual es casi insignificante en la sociedad cubana); y en casos que se encuentran, por las causas que sean, en situaciones de acentuada vulnerabilidad económica y cultural que pudiera ejercer, o vivenciarse, con un efecto coercitivo sobre el comportamiento cercano al que ejerce la violencia.

En la sociedad cubana, es difícil decir que la inmensa mayoría de los sujetos que entraron a la prostitución fue porque no tenían alternativa. Cierto es que a partir de la última década del pasado siglo, con la crisis y las reformas, para algunos segmentos sociales las alternativas a seguir se estrechan, mientras se amplían para aquellos en 
situaciones socioeconómicas y culturales favorables. Sin embargo, como ha observado Giddens ${ }^{43}$ siempre que haya dos o más posibles opciones de proceder, entra en juego, generalmente, el carácter activo del sujeto, su capacidad de reflexionar, e intentar dominar de algún modo, las circunstancias en que se desenvuelve su vida; su poder real para decidir, escoger el rumbo a seguir, así como posturas a adoptar, conocimientos, experiencias, creencias, valores, normas, actitudes, aspiraciones; aspectos todos que se forman en interacción con otros en el complejo proceso de socialización; a su vez bajo el influjo de las condiciones, rasgos y tendencias de la sociedad.

En tal sentido es cierto que el desplome del llamado socialismo real, sistema que había sido referente para amplios segmentos sociales en Cuba, unido al agravamiento del bloqueo de Estados Unidos contra Cuba, y algunas insuficiencias internas, en conjunto contribuyen a una crisis que no sólo desestructuró la economía y afectó profundamente los medios sociales y las prácticas habituales de las familias para la satisfacción de las necesidades básicas ${ }^{44}$; también hizo inefectivos múltiples aspectos de la vida social que contienen, y funcionan como reglas implícitas para el comportamiento social. Por cuanto, diversos grupos sociales en Cuba experimentan pérdida de referentes, inseguridad ontológica, afectaciones en la sensación de futuridad y en la capacidad de prever, proyectar metas y de orientarse hacia ellas ${ }^{45}$, situación aún no superada totalmente.

Actualmente se evidencia en algunos segmentos sociales crisis de valores que se visibiliza en las indisciplinas, la simulación, el individualismo, el egoísmo, la debilidad o pérdida del valor trabajo, la corrupción en diversas formas, entre otros fenómenos de naturaleza negativa (Fabelo Corzo, J. R., Fernández Retamar R., 2014; entre otros),

43. GIDDENS, Antony. Et al.

44. MARTÍN FERNÁNDEZ, C., PERERA PÉREZ, M., DÍAZ PÉREZ, M. Introducción al estudio de la Vida Cotidiana desde la Psicología Social. En: Psicología Social y Vida Cotidiana. Selección de Lecturas. Primera parte. Editorial Félix Varela. La Habana, 2004, obra referenciada.

45. ALONSO TEJADA, Aurelio. El laberinto tras la caída del muro. Argentina: CLACSO, 2009. En: http://site.ebrary.com/lib/vepingsp/Doc?id=10398316

Facultad de Derecho y Ciencias Sociales - Universidad de Valparaíso - Chile 
que se han insertado en la vida cotidiana de múltiples sujetos, algunos con cierta inclinación a asumirlos como naturales e insuperables; con repercusiones negativas en los procesos de reproducción, apropiación, configuración activa de los esquemas de valores y normas de comportamiento en la cotidianidad, y por consiguiente en la autorregulación y regulación social de la conducta; lo que ha favorecido, a la vez, el despliegue de formas variadas de transgresión social, entre ellas la prostitución.

Debemos tener en cuenta que en Cuba indudablemente continúan y se profundizan políticas sociales universalistas como la gratuidad de los servicios de educación y salud alcanzándose logros reconocidos por organismos internacionales, representantes del ámbito académico y político, y otros. Además, en la sociedad cubana es una práctica político social arraigada, con el proyecto social emancipatorio, no dejar desamparado a ningún sujeto. Para ello se encauzan diferentes acciones de protección y asistencia a los grupos menos favorecidos que se mantienen hasta la actualidad y alcanzaron su clímax en el marco de los Nuevos Programas Sociales (NPS) en la primera década del presente siglo. La difícil situación económica, empeorada por el todavía principal obstáculo al desenvolvimiento de la economía cubana (el bloqueo económico norteamericano a Cuba) comenzó a dejar una huella desfavorable en diversos grupos sociales. Por su parte, las reformas introducidas a partir de la década final del siglo XX, y profundizadas con el proceso en marcha de actualización del modelo económico y social cubano, contribuyen primero a detener la caída de la economía, y luego un modesto crecimiento de ésta, que facilita la continuidad de políticas sociales universalistas, sus logros, y en general tratar de alcanzar ideales contenidos en el proyecto emancipatorio cubano.

No obstante, con la crisis y las reformas la sociedad cubana experimenta cambios estructurales, que tocan las relaciones de propiedad, la estructura socioclasista, y las formas de redistribución de la riqueza social; lo cual viene acompañado de procesos de reestraficación social ${ }^{46}$.

46. ESPINA PRIETO, Mayra Paula. Políticas de atención a la pobreza y la desigualdad: examinando el rol del Estado en la experiencia cubana. Argentina: CLACSO, 2010.

Revista de Ciencias Sociales - Número 69 (2016) - Universidad de Valparáíso - ISSN 0716-7725-Valparaíso, Chile 
La sociedad cubana actual es mucho más heterogénea con clases y estratos sociales formados, cuyos niveles de consumo y poder real para satisfacer determinadas necesidades en condiciones de un mayor papel de las relaciones monetario mercantiles, dependería de la magnitud de los ingresos. De modo que tendríamos grupos sociales, en situaciones socioeconómicas ventajosas entre los que se encuentran los que acceden frecuentemente a ingresos en divisas, cualquiera que sea su fuente (remesas familiares, empleo en turismo, empresas mixtas, etc.), algunos de los más prósperos trabajadores privados individuales, de los dueños de pequeños y medianos negocios privados urbanos, y de los campesinos que pueden contratar fuerza de trabajo.

También tenemos grupos sociales en situaciones socioeconómicas desventajosas, entre los que, según Mayra Espina, existen entre otros individuos y familias que no cuentan con redes familiares de ayuda que amplíen sus ingresos y viven de una jubilación, o un salario mínimo; familias numerosas, monoparentales maternas, o cualquier otro tipo en las que se verifica una baja o nula integración al trabajo remunerado, dependencia de los fondos sociales de consumo y una insuficiencia o escasa presencia de activos tangibles e intangibles que les permita acceder en condiciones de igualdad a las fuentes de empleo y de prosperidad existentes y abiertas por las reformas.

El desempleo, subempleo, la ausencia o insuficiencia de ingresos provenientes del trabajo, las dificultades para el acceso a una vivienda confortable y su equipamiento, el incremento de los hogares dirigidos por mujeres, entre otros aspectos no son determinantes de forma aislada y por sí mismos de la prostitución, pero si se entrelazan, junto a aspectos de la subjetividad de los actores pueden generar, reproducir y reforzar situaciones de vulnerabilidad social y de pobreza. Con ello estamos en presencia de algunos de los factores que inciden en el aumento de la oferta de prostitución; factores que revelan una contradicción entre la estructura cultural y la social, por mínimo que sea su alcance en comparación con otras sociedades.

Sin embargo, encontramos ciertos sujetos en prostitución, cuyo punto de partida es diferente. Algunos califican dentro de los grupos sociales en situaciones socioeconómicas y culturales ventajosas. Lo anterior pudiera tener una explicación comprensible en lo siguiente:

Facultad de Derecho y Ciencias Sociales - Universidad de Valparaíso - Chile 
en el marco del proyecto emancipatorio cubano, se ha tratado de formar sujetos que asuman, y se comporten conforme a expectativas de consumo y de trabajo socialmente responsables, congruente con la característica de la sociedad. Pero, en algunos sujetos se observa una escasa relación entre crecientes aspiraciones reforzadas hacia el consumo de bienes y servicios, y la debilidad o pérdida del valor trabajo. Lo último bajo la influencia histórica y actual del acceso a bienes y servicios con un bajo esfuerzo individual, desligado de su aporte real a la creación de la riqueza social, unido a la baja capacidad adquisitiva del salario, y el desequilibrio entre calificación e ingresos reales ${ }^{47}$. Además, en la configuración y reforzamiento de necesidades y aspiraciones inclinadas hacia el consumo de bienes materiales, e incluso hacia el consumismo consustancial al capitalismo influye el incremento de la emigración y los viajes al exterior cualquiera que sea su tipo, la reunificación familiar, el aumento de la visitas y de las remesas a familiares Cuba de los residentes en otros países. Todo ello unido al ascenso del turismo y de la inversión extranjera, una mayor presencia y uso de tecnologías de la información (computadoras, Internet, correo electrónico, celulares, DVD, entre otras), que en conjunto son generadores de vínculos sociales que facilitan un mayor intercambio cultural entre las sociedades capitalistas y la nuestra.

Los cambios ya en marcha, y las continuidades, en las relaciones entre Cuba y los Estados Unidos a partir del año 2014, no obstante su lado positivo, suponen mayores desafíos para el proyecto emancipatorio cubano de construcción de un tipo de sociedad diferente de la capitalista en cuanto a modo y estilo de vida.

En situaciones donde se estrechan, o el sujeto asume como insuficientes, los medios moral y legalmente válidos para satisfacer las necesidades y aspiraciones cada vez más crecientes, algunos han convertido, y naturalizado, a la prostitución en medio bajo el supuesto de que conlleva un menor esfuerzo individual. Otros sujetos se concentran en vivir el presente; y aunque los medios para hacerlo son variados, puede influir en la prostitución cuando se trata de vivir lo mejor que se pueda el aquí y el ahora, con bajo esfuerzo individual, dentro o fuera de Cuba.

47. ESPINA M., 2001, Et al, obra referenciada.

Revista de Ciencias Sociales - Número 69 (2016) - Universidad de Valparáíso - ISSN 0716-7725-Valparáiso, Chile 
Cabe añadir que algunos segmentos sociales, especialmente jóvenes, de estratos sociales diversos, han convertido, y mucha veces naturalizado, la prostitución en un medio para llegar a otras sociedades, bajo el supuesto de que accederán fácilmente a satisfactores adecuados de ciertas necesidades y aspiraciones de modo y estilo de vida en ocasiones con un fuerte matiz consumista. En relación con todo lo anterior, cuando el individuo queda fuera de la escuela y el trabajo, y algunos al menos durante un periodo más o menos prolongado, han salido de estas instituciones a una edad donde debían estarlo, se debilita o pierde el influjo positivo de significativos reguladores sociales. Ello pudiera afectar negativamente la subjetividad y comportamiento de los sujetos, afectaciones que luego son difíciles de revertir; especialmente si se combina con la entrada a grupos informales que ejerzan una influencia negativa, contradictoria, ambivalente sobre sus miembros, y la familia no cumple adecuadamente con las importantes funciones que le corresponden.

Como sabemos, esta es una cuestión mucho más complicada; escuela, trabajo, familia, grupos informales de pertenencia o referencia pueden influir simultáneamente en sentido positivo, y también, pudieran darse influencias contradictorias y ambivalentes al interior y entre esas intuiciones y grupos sociales; en cualquier caso cruzadas por procesos económicos, laborales, familiares, entre otros que ocurren en la sociedad.

Las familias cubanas son beneficiarias de los logros materializados dentro del proyecto social cubano, y las reglas relativas a sus funciones como célula fundamental de la sociedad están definidas legal y moralmente; pero no escapan a los problemas acentuados con la crisis y las reformas. Al respecto, algunos autores focalizan múltiples contradicciones en las interacciones intrafamiliares y en las relaciones sociedad-familias generadoras de prácticas individuales y familiares para adaptarse proactivamente a las difíciles circunstancias, algunas de ellas abiertamente transgresoras de la normatividad social.

La influencia simultánea de saberes, valores, actitudes, normas, símbolos, ideologías y estilos de vida, siempre que, obviamente, se contradigan entre sí, debilitan la labor formativa, educativa de los agentes socializadores oficializados y la capacidad de los sujetos,

Facultad de Derecho y Ciencias Sociales - Universidad de Valparaíso - Chile 
especialmente los más jóvenes, para discernir entre lo que es bueno o malo, deseable o no. Así, por ejemplo, en la escuela se trata de formar comportamientos ajustados a valores como la austeridad, pero el incremento del contacto cultural con sociedades capitalista más condicionantes internas empujan en sentido opuesto, o sea, hacia la no sobriedad, el consumismo, tanto como aspiración o deseo, como en un obrar que se ancla en prácticas cotidianas que tienden a ser asumidas por algunos sujetos como válidas y deseables.

Aunque este es un asunto que requiere ser profundizado en nuestras circunstancias, es posible afirmar que la presencia de estratos sociales, con capacidades de consumo diferentes, en circunstancias difíciles donde se refuerza el contacto cultural con sociedades capitalistas, y la mayor presencia de las relaciones monetarias mercantiles, y consiguientemente el poder efectivo y simbólico del dinero, favorece que algunos segmentos de los estratos sociales en Cuba con mayor capacidad de consumir bienes y servicios, adquieran y proyecten una imagen de status y poder privilegiado asociado a la posesión de bienes materiales y especialmente del dinero cualquiera que sea su fuente; y con ello, en contradicción con lo oficialmente buscado, tendencialmente orientan hábitos de compra, definen patrones de consumo e influyen en los procesos de configuración de necesidades, aspiraciones, proyectos y estilos de vida no siempre ajustados a los valores y a las expectativas de modo y estilo de vida contenidos en el proyecto social cubano. Consumir bienes y servicios es indispensable para satisfacer necesidades básicas, —irreducibles, por cierto—, a comida, agua, vestuario, casa, entre otras de carácter material, pues incluye las no menos importantes necesidades espirituales, todas condicionadas socioculturalmente, y es una relación social relevante repleta de significados subjetivos.

Generalmente, mientras más visible, y expuesto a la valoración de otros, sea lo que el sujeto consume y utiliza para satisfacer necesidades, ejemplo la vestimenta, mayor importancia cobra estar a tono con los modos de consumo de la sociedad o grupo, y la cuestión de los medios que lo posibiliten. Aunque esto es válido para cualquier clase, estrato y segmento social, y no obstante la no linealidad en las relaciones entre estos, la jerarquía movediza de sus necesidades o aspiraciones y los medios que se usan para satisfacerlas, es posible afirmar que los

Revista de Ciencias Sociales - Número 69 (2016) - Universidad de Valparáíso - ISSN 0716-7725-Valparaíso, Chile 
jóvenes son el segmento que puede experimentar mayor sufrimiento, por el golpe a su autoestima y a su identidad, cuando tienen, o entienden que tienen, un bajo acceso a satisfactores de necesidades, que asumen como adecuados.

Un aspecto a considerar es que la sociedad cubana es mucho más libre sexualmente. Sin embargo, una de sus derivaciones ha sido el incremento de la promiscuidad sexual, con una pérdida extrema de la capacidad reguladora de la moral sexual, lo que puede facilitar el tránsito hacia la venta del cuerpo; y también junto a la acentuación de la conversión del otro en objeto, allana el camino al despliegue de los clientes de la prostitución, y de diferentes formas de intermediación entre la compra y la venta de servicios sexuales.

Respecto al ascenso de la tolerancia social y familiar es deseable, en tanto conlleva la quiebra de prejuicios y tabúes que laceran derechos socialistas fundamentales. No obstante, en lo que respecta a la prostitución, al tiempo que existe un amplio rechazo al abuso sexual o corrupción de menores de edad, ocurre una creciente tolerancia familiar y social hacia la prostitución de jóvenes y adultos, y hacia otros fenómenos sociales negativos; expresión de la tolerancia compleja, descrita por Vinuesa y Díaz, en específico cierta tolerancia transgresora, en la cual los límites entre tolerancia y aceptación de la transgresión son difusos, bajo lo cual subyace la pérdida de la autorregulación moral, un dejar hacer para evadir responsabilidades individuales, familiares y sociales; y en algunos casos tratar de alcanzar o consolidar situaciones de impunidad, privilegio y prebendas ${ }^{48}$.

Nada de lo dicho quiere decir que ser intolerante en su versión extrema con respecto a la prostitución en general sea el único y ni siquiera el mejor camino para desestimularla, aunque esto es una cuestión de grados. Es sabido que la intolerancia, separada de acciones que lleven al cambio de las circunstancias de vida de los sujetos produce resultados contraproducentes.

48. ESPINA, M., 2001, Et al, obra referenciada.

Facultad de Derecho y Ciencias Sociales - Universidad de Valparaíso - Chile 


\section{Conclusiones}

Entre los factores que pueden incidir en la prostitución en la sociedad cubana actual encontramos aquellos que corresponden al marco regulatorio jurídico-social directo, que parten de los objetivos expresos del Estado cubano de desestimular, reducir al mínimo, y si fuera posible erradicar la prostitución en toda sus manifestaciones.

Un segundo grupo de factores que tienen potencialidad para influir en el fenómeno social podemos incluirlos en el marco regulatorio político social subyacente, esto es, el sistema de relaciones sociales legitimadas oficialmente. Ello con sus avances sociales, y desafíos socioeconómicos y culturales.

Las políticas sociales de cobertura universalista, y otras que permiten sostener logros, y tratan de establecer oportunidades de inserción social y prosperidad individual, sin que logren remover totalmente la lacerada capacidad de algunos sujetos de solventar ciertas necesidades en los marcos de las reglas implícitas de movilidad social, así como desigualdades históricas y actuales instaladas en las relaciones sociales.

El marco regulatorio social, o sea el poder de las fuerzas reales de la cotidianidad en el establecimiento de normas de comportamiento, está condicionado por las condiciones objetivas y subjetivas en que se producen los procesos de reproducción y apropiación de las reglas, cualquiera que sea su índole.

\section{BIBLIOGRAFÍA}

ALONSO, Tejada, Aurelio. El laberinto tras la caída del muro.

Argentina: CLACSO, 2009. En: http://site.ebrary.com/lib/ vepingsp/Doc? id $=10398316$

ANGUITA, Concepción. El tráfico ilegal de seres humanos para la

explotación sexual y laboral: la esclavitud del siglo XXI.

Nómadas. Revista Crítica de Ciencias Sociales y Jurídicas. 15(1): 3-16, 2007. España: Universidad Complutense de Madrid, 2007.

Revista de Ciencias Sociales - Número 69 (2016) - Universidad de Valparáíso - ISSN 0716-7725-Valparaíso, Chile 
BERMÚDEZ, Ángela; GAVIRIA, Ana Milena; FERNÁNDEZ, Hamilton. Estilos psicológicos de personalidad en un grupo de mujeres adultas jóvenes dedicadas a la prostitución "prepago" en la ciudad de Medellín. Chile: Red Terapia Psicológica, 2009. Pp. 3-10. CHEJTER, Silvia. Lugar común: la prostitución. Argentina: Eudeba, 2011.

__ Discurso pronunciado por el presidente Fidel Castro Ruz en el acto por el aniversario 40 de la constitución de la Policía Nacional Revolucionaria, efectuado en el teatro Carlos Marx, 5 de enero de 1999, Año del 40 aniversario del triunfo de la Revolución. Granma Internacional Digital. La Habana. Cuba.

DORAIS, Michel. Intimidad en venta: ¿cómo se llega a ser trabajador sexual? México: Red Desacatos, 2006.

ELIZALDE, Rosa M. Flores desechables. ¿Prostitución en Cuba? Editora Abril, Cuba. 1996.

ESPINA M., Martín L., y Núñez, L., 2001. Reajuste económico y cambios socioestructurales. Revista Temas. 3ra época, número 21- 2001.

FIGUERAS Francisco, Cuba y su evolución colonial, Editorial Cenit S.A., La Habana, 1907.

GIDDENS, Anthony. La constitución de la sociedad. Bases para la teoría de la estructuración. Amorrortu editores S. A., Buenos Aires, 1985.

HOWELL, Jayne. Las Lupes oaxaqueñas: obligaciones familiares y económicas. Editorial: Red Desacatos, 2006.

IZQUIERDO, Canosa, R., La reconcentración. 1896-1897, Ediciones Verde Olivo, La Habana, 1997; Vera, Ana. Estudiar la Familia.

Un repaso. Temas $\mathrm{N}^{\circ}$ 31: 101-110, octubre-diciembre de 2002; Barcia

Zequeira, M. C. Una sociedad en Crisis: La Habana a finales del siglo XIX. Editorial de Ciencias Sociales, La Habana, 2009.

JAYNE, Howell. Las Lupes oaxaqueñas: obligaciones familiares y económicas. Editorial: Red Desacatos, 2006.

LAMO DE ESPINOSA, Emilio. Delitos sin víctima. Orden Social y Ambivalencia moral. Madrid, Alianza Editorial, 1993.

__ Ley No 62 de 1987, vigente Código Penal, Libro I. Título XI. El Estado Peligroso y las medidas de seguridad, Artículo 72; 73, c., 2; 75; 76; 77. Ministerio de Justicia, 1997.

Facultad de Derecho y Ciencias Sociales - Universidad de Valparaíso - Chile 
LÓPEZ CIVEIRA, F., “La República (1899- 1959)”. En: López Civeira, F.; Loyola O.; Silva L. "Cuba y su Historia”. Editorial Félix Varela. La Habana, 2005. pp. 117-216.

LOYOLA, Vega, O., La sociedad insular. En: Cuba y su historia, Editorial Félix Varela, La Habana, 2005:23

FERNÁNDEZ, Martín C., PERERA Pérez, M., DÍAZ Pérez, M. Introducción al estudio de la Vida Cotidiana desde la Psicología Social.

En: Psicología Social y Vida Cotidiana. Selección de Lecturas. Primera parte. Editorial Félix Varela. La Habana, 2004.

MENA, Luz M. Raza, género y espacio: las mujeres negras y mulatas negocian su lugar en La Habana durante la década de 1830.

Colombia: Red Revista de Estudios Sociales, 2009: 10 http:// site.ebrary.com/lib/vepingsp/Doc?id $=10306750$

MUSTELIER CARMENATY, Sandra. La prostitución desde el Derecho, 2002. Mimeo.

REUS, María Esther. "Quinto informe nacional sobre el enfrentamiento jurídico penal a la trata de personas y otras formas de abuso sexual, 15 de octubre de 2013, disponible en el sitio web del Ministerio de Relaciones Exteriores www.cubaminrex.cu

ROMI, Juan Carlos. La prostitución. Enfoque psiquiátrico, sexológico y médico-legal. En: http://www.marietan.com/contac.htm . [24de mayo de 2010].

SAWYER, Steven y otros. Attitudes Towards Prostitution Among Males: A 'Consumers' Report', Current Psychology, 10461310, Winter 2001, Vol. 20, Fascículo 4.

VERA, Ana, Estudiar la Familia. Un repaso. Temas \# 31: 101-110, octubre-diciembre de 2002. 